\title{
Fibra de casca de laranja como substituto de gordura em pão de forma
}

\author{
Citrus peel fiber and its application as a fat substitute in loaf brad
}

Liana Stoll ${ }^{\mathbb{I}}$ Simone Hickmann Flôres ${ }^{\mathrm{I}}$ Roberta Cruz Silveira Thys ${ }^{{ }^{*}}$

RESUMO

Os subprodutos da indústria de frutas possuem alta qualidade nutricional, de forma que sua transformação em ingredientes para aplicação em produtos alimentícios é de grande importância. No presente estudo, foram avaliados os efeitos da substituição total da gordura em pães de forma através da utilização de fibra de casca de laranja (0 a 5\%), um subproduto industrial. A adição da fibra de laranja foi combinada ao uso de $\alpha$-amilase (10 a 50ppm), através de um planejamento experimental fatorial completo $2^{2}$. Para fins de comparação, foi elaborada uma formulação controle, sem fibras, sem enzimas e com $2 \%$ de gordura. A qualidade dos pães foi avaliada através de análises de vida útil (por índice de retrogradação, DSC), volume, cor, atividade de água e análise sensorial. A fibra de laranja, associada ao uso de enzimas, contrapôs os possíveis efeitos negativos causados pela ausência da gordura, para as concentrações de fibra e enzima estudadas, permitindo a obtenção de pães isentos de gordura e com fibras. A presença de $2,5 \%$ de fibra de laranja combinada ao uso de 30 ppm de $\alpha$-amilase gerou um pão com volume $23 \%$ maior ao alcançado pela amostra controle e com índice de aceitação em torno de $80 \%$.

Palavras-chave: fibra da casca da laranja, subproduto, alfaamilase, vida útil, indice de retrogradação.

\section{ABSTRACT}

Food industry byproducts have high nutritional quality, so that its transformation into ingredients for use in food products is of great importance. This study aimed to analyze the effects of total fat replacement in loaf bread, by adding orange peel fiber (0-5\%), an industrial byproduct. The use of citrus fiber was combined with the addition of $\alpha$-amylase (10 to 50ppm), by using a complete experimental factorial design $\left(2^{2}\right)$. A formulation containing $2 \%$ of fat, without citrus fiber and enzyme was used as control. The breads quality was measured by analyzing shelf life (by Retrogradation Index determination), volume, crumb color, water activity and sensorial parameters. The citrus fiber in association with the addition of $\alpha$-amylases neutralized the potential negative effects that the removal of fat could cause, considering the ranges of fiber and enzyme studied, allowing to obtain fat-free breads with fibers. The presence of $2.5 \%$ of citrus fiber combined with the use of 30ppm of $\alpha$-amylase increased the volume of breads by $23 \%$, comparing with the control formula, and had an acceptance index of around $80 \%$

Key words: orange pell fiber, by-product, alfa-amylase, shelf-life, retrogradation index.

\section{INTRODUÇÃO}

A busca por uma alimentação saudável faz com que os consumidores procurem por produtos que aliem saúde ao prazer de um alimento palatável. Este perfil de consumidores impulsiona o desenvolvimento de produtos com redução substancial de gordura, sem prejuízo ao seu sabor e qualidade (FORKER et al., 2012).

As gorduras exercem grande influência nos processos de panificação, principalmente no volume do pão e na manutenção de sua qualidade pós-cocção. A dispersão das partículas de gordura na massa permite que o pão fique macio e palatável por um período de tempo prolongado, além de contribuir com a liberação de um perfil aromático característico (STAUFFER, 2007). Apesar de sua importância na tecnologia de panificação, o alto consumo de gordura está relacionado a diversas doenças, como doenças cardiovasculares, obesidade e outras disfunções no organismo (BABOOTA et al., 2013).

IInstituto de Ciência e Tecnologia de Alimentos (ICTA), Universidade Federal do Rio Grande do Sul (UFRGS), 90040-060, Porto Alegre, RS, Brasil. E-mail: roberta.thys@ufrgs.br.*Autor para correspondência. 
Segundo BENASSI et al. (2001), a maneira mais tradicional de se obter redução calórica em produtos de panificação é através da substituição parcial dos ingredientes calóricos por fibras. A ingestão de fibras gera inúmeros efeitos benéficos à saúde e, assim, a busca por novas fontes deste ingrediente vem aumentando fortemente (SANTANA; GASPARETTO, 2009; FERNANDEZ-LÓPEZ et al., 2009). A sua alta capacidade de retenção de água a torna um potencial substituto de gordura, e, portanto, tem sido alvo de estudo em diversos alimentos (BORTOLUZZI, 2009; ROMERO-LOPEZ et al., 2011).

$\mathrm{O}$ processo industrial de suco de laranja gera grande quantidade de resíduos como cascas, sementes e poupa, de forma a representar fonte de fibra em potencial. Aproximadamente $50 \%$ do peso da fruta é subutilizado e rico em fibras (SANTANA \& GASPARETTO, 2009), tornando sua exploração interessante, não somente do ponto de vista econômico, como também ambiental.

A adição de fibras em produtos de panificação tem sido amplamente estudada, onde efeitos como alteração das propriedades viscoelásticas da massa, redução de volume e da maciez do pão são relatados (WANG et al., 2002). A fim de reduzir tais efeitos, é comum o uso de enzimas que tenham efeito sobre a reologia da massa (KATINA et al., 2005). É importante ressaltar que o envelhecimento do pão está intimamente relacionado ao endurecimento (ou falta de maciez) resultante da sinerese, a qual pode ser monitorada através do grau de retrogradação da amilopectina (PURHAGEN et al., 2012).

Considerando a atual tendência por produtos ricos em fibras e com teor reduzido de gordura, aliada à importância de minimizar os impactos ambientais gerados pela indústria de alimentos, este trabalho tem como objetivo verificar os efeitos da utilização de fibra de laranja comercial na substituição de gordura em pão de forma, combinado ao uso de enzimas.

\section{MATERIAL E MÉTODOS}

A fibra de casca de laranja amarga (Citrus aurantium L., cubos $2 \times 5 \mathrm{~mm}$ ) foi adquirida da empresa Tango Alimentos (Natal, RN). O glúten vital de trigo, o preparado de enzimas Spring FreshG ( $\alpha$-amilase bacteriana-12.500SKB g ${ }^{-1}$ e $\alpha$ -amilase fúngica-320UAMGF $\mathrm{g}^{-1}$ ), o ácido ascórbico e os monoglicerídeos (MONO-90M/0,2\%-0,4\%) foram adquiridos através de doação pela empresa Granotec (Curitiba, PR). A farinha de trigo utilizada foi da marca Rosa Branca (cinzas: 0,55\%; proteína: 11,25\%; umidade: $14,9 \%$; padrões alveográficos: $\mathrm{W}=245, \mathrm{P}=65, \mathrm{~L}=130$, Número de Queda: 415s), do Moinho Cruzeiro do Sul (São Luís-MA). As demais matérias-primas foram adquiridas no mercado local de Porto Alegre (RS).

A fim de realizar corretamente a hidratação da fibra de laranja com água, foi realizada análise da Capacidade de Retenção de Água (CRA) da fibra, de acordo com o método de FERNÁNDEZ-LÓPEZ et al. (2009).

As formulações dos pães de forma foram determinadas através de planejamento experimental fatorial $2^{2}$ com três repetições no ponto central. As variáveis independentes testadas foram a concentração de fibra de laranja $(0 \% ; 2,5 \%$; e $5 \%)$ e a concentração da $\alpha$-amilase (10ppm; 30ppm; e 50ppm). A faixa de fibra de laranja estudada deu-se através de testes de panificação preliminares, onde foram testadas concentrações de 0 a $10 \%$ de fibra, e a faixa de enzima através da indicação de uso do fornecedor.

O preparo da massa dos pães ocorreu através do método de massa direta, com batimento (masseira GPaniz) de aproximadamente 10 minutos. Nas formulações com fibra de laranja, esta foi adicionada em sua forma hidratada (com quantidade de água proporcional a sua CRA), antes da adição da água da masseira. A massa foi dividida em porções de $400 \mathrm{~g}$, seguida de boleamento manual e modelagem (modeladora GPaniz). Em seguida, os pães foram colocados em formas, e em câmara de fermentação (Venâncio, modelo AC20T) a $30^{\circ} \mathrm{C}$ e umidade relativa de $80 \%$, por uma hora. O forneamento foi realizado em forno turbo elétrico (Tedesco/modelo FTT150E), a $180^{\circ} \mathrm{C}$ por 25 minutos e, após uma hora de resfriamento, os pães foram embalados em sacos plásticos de polipropileno, selados termicamente e armazenados à temperatura ambiente.

Além das formulações determinadas pelo planejamento experimental, também foi realizada uma formulação controle, elaborada com gordura, sem enzimas e sem adição de fibra de laranja (Tabela 1).

Através de um planejamento experimental, foram analisadas as características que traduzem a qualidade dos pães (volume, atividade de água, coloração do miolo, análise sensorial), e a evolução de sua vida útil, através do índice de retrogradação, em um período de sete dias. A calorimetria diferencial de varredura (DSC) é a técnica mais usada para detectar as transições térmicas de primeira (fusão) e segunda ordem (vítreas) em diversos materiais e, quando aplicada a materiais amiláceos, fornece 
Tabela 1 - Formulações testadas de pão de forma.

\begin{tabular}{|c|c|c|c|c|c|c|}
\hline Ingredientes & $\mathrm{F} 1$ & $\mathrm{~F} 2$ & F3 & F4 & F5 & Controle \\
\hline Farinha de trigo & $100 \%$ & $100 \%$ & $100 \%$ & $100 \%$ & $100 \%$ & $100 \%$ \\
\hline Água & $69 \%$ & $62 \%$ & $70 \%$ & $67 \%$ & $71 \%$ & $65 \%$ \\
\hline Açúcar & $4 \%$ & $4 \%$ & $4 \%$ & $4 \%$ & $4 \%$ & $4 \%$ \\
\hline Glúten vital de trigo & $2,5 \%$ & $2,5 \%$ & $2,5 \%$ & $2,5 \%$ & $2,5 \%$ & $2,5 \%$ \\
\hline Fermento biológico seco & $2 \%$ & $2 \%$ & $2 \%$ & $2 \%$ & $2 \%$ & $2 \%$ \\
\hline Sal & $2 \%$ & $2 \%$ & $2 \%$ & $2 \%$ & $2 \%$ & $2 \%$ \\
\hline Monoglicerídeos & $0,20 \%$ & $0,20 \%$ & $0,20 \%$ & $0,20 \%$ & $0,20 \%$ & $0,20 \%$ \\
\hline Ácido ascórbico & 80ppm & 80ppm & 80ppm & 80ppm & 80ppm & 80ppm \\
\hline Enzimas & $10 \mathrm{ppm}$ & $10 \mathrm{ppm}$ & $50 \mathrm{ppm}$ & $50 \mathrm{ppm}$ & $30 \mathrm{ppm}$ & 0 \\
\hline Fibra de laranja & 0 & $5 \%$ & 0 & $5 \%$ & $2,50 \%$ & 0 \\
\hline Gorduravegetal hidrogenada & 0 & 0 & 0 & 0 & 0 & $2 \%$ \\
\hline
\end{tabular}

medidas quantitativas do fluxo de calor, associado à gelatinização e à retrogradação do amido, onde a presença dos picos endotérmicos é um indicativo da fusão da molécula (SINGH et al., 2007). O DSC (Differential Scanning Calorimeter), calorímetro diferencial de varredura (Perkin-Elmer DSC 6000, Modelo 523A), foi utilizado para verificar a gelatinização e a retrogradação do amido, medidas através das endotermas obtidas pela análise, em triplicata, da amostra fresca (obtida no dia de seu preparo, não fermentada) (gelatinização) e da amostra, após sete dias de armazenamento sob refrigeração (retrogradação), segundo a metodologia descrita por LEÓN et al. (1997). Para tanto, uma amostra de massa fresca de pão $(18-20 \mathrm{mg})$ obtida no dia do seu preparo, sem a etapa de fermentação e forneamento, foi inserida em cápsula de alumínio e selada. Uma cápsula vazia foi usada como referência. Após serem colocadas no interior do equipamento, as amostras foram aquecidas de 25 a $100^{\circ} \mathrm{C}$, a uma taxa de aquecimento de $10^{\circ} \mathrm{C} \mathrm{min}^{-1}$, mantidas por 5 minutos a temperatura de $100^{\circ} \mathrm{C}$, para determinação da entalpia de gelatinização. Após, as cápsulas foram retiradas do equipamento e armazenadas sob refrigeração $\left(5^{\circ} \mathrm{C}\right)$ com o intuito de acelerar o processo de retrogradação do amido. Após sete dias de armazenamento sob refrigeração, as amostras foram novamente analisadas em DSC de 25 a $110^{\circ} \mathrm{C}$, a uma taxa de aquecimento de $10^{\circ} \mathrm{C} \mathrm{min}^{-1}$, para determinação da entalpia de retrogradação. Os parâmetros medidos foram: temperatura inicial (To), temperatura de pico endotérmico (Tp), temperatura de conclusão $(\mathrm{Tc})$, entalpia de gelatinização $(\Delta \mathrm{Hgel}$, $\mathrm{J} \mathrm{g}^{-1}$ ) e entalpia de retrogradação $\left(\Delta\right.$ Hret, $\left.\mathrm{J} \mathrm{g}^{-1}\right)$. O Índice de Retrogradação é definido como a razão entre as entalpias de gelatinização e as entalpias de retrogradação (LEÓN et al., 1997).
$\mathrm{O}$ volume específico $\left(\mathrm{cm}^{3} \mathrm{~g}^{-1}\right)$ dos pães foi determinado uma hora após seu forneamento, em triplicata, pelo método descrito por SILVA et al. (1998).

A atividade de água dos pães foi medida no dia do seu preparo, uma hora a pós o forneamento, e após sete dias. Para a análise, realizada em triplicata, uma porção da região central do pão (miolo) foi inserida no equipamento AquaLab (Modelo $3 \mathrm{TE}$, a $25^{\circ} \mathrm{C}$ ).

A determinação da cor do miolo dos pães foi realizada em duplicata através do método CIE (sistema $\mathrm{L}^{*} \mathrm{a} \mathrm{b}^{*}$ ), em colorímetro (Konica-Minolta CR 400 Chroma Meter, Japão). O colorímetro mede a cor através de três parâmetros: $L^{*}$, que varia de 100 (branco) para zero (preto), b, que varia de azul (negativo) para amarelo (positivo) e a, que varia de verde (negativo) para vermelho (positivo).

Os pães elaborados foram avaliados através de análise sensorial composta por um painel de 50 provadores não treinados. Um dia após seu preparo, as amostras foram servidas simultaneamente, utilizando uma ficha com escala hedônica verbal de 9 pontos, variando de 1 (desgostei muitíssimo) até 9 (gostei muitíssimo) para os atributos "cor do miolo", "aroma", "sabor", "textura" e "aceitação global".

Os dados foram analisados através de ANOVA e teste de Tukey para diferença de médias, utilizando o Software Statistica 7.0.

\section{RESULTADOS E DISCUSSÃO}

Nas faixas de concentração de fibra e enzima estudadas, não se obteve modelo matemático para a metodologia de superfície de resposta, indicando que os dados experimentais não são explicados matematicamente. Avaliou-se, desse modo, a influência da fibra e enzima das formulações elaboradas segundo o planejamento experimental, por 
Análise de Variância (ANOVA), para as diferentes respostas. Para a análise dos resultados, foi realizada a média dos pontos centrais, identificada nos resultados como "F5".

A tabela 2 apresenta os valores do parâmetro $\mathrm{L}^{*}$ e das coordenadas cromáticas $\mathrm{a}^{*} \mathrm{e} \mathrm{b*}$ da análise colorimétrica do miolo dos pães. A adição da fibra de laranja aumentou significativamente os valores do parâmetro b* das amostras F2, F4 e F5, quando comparados com a amostra controle, o que indica a presença de miolo mais amarelado $\left(\mathrm{b}^{*}\right.$ positivo).

Não foi observada diferença estatística entre os tratamentos para o Índice de Retrogradação (IR) (Tabela 3), o que sugere que os fenômenos de sinerese ocorreram de forma semelhante para todas as formulações. O IR indica a tendência ao processo de ressecamento do pão, pois está intimamente relacionado com a sinerese, provocada pela retrogradação do amido, onde a reassociação das cadeias de amilopectina provoca a saída da água do sistema (LEÓN et al., 2002; CALVEL \& WIRTZ, 2001; PURHAGEN et al., 2012). A presença da gordura evita o ressecamento dos pães (STAUFFER, 2007), fato que reduziria o fenômeno de retrogradação, porém a formulação Controle não apresentou IR inferior às demais. Este fato pode ser explicado através da adição de enzimas nos demais tratamentos. LEÓN et al. (2002) estudaram a influência de misturas de enzimas contendo $\alpha$-amilase e lipase em pães e verificaram efeito benéfico na manutenção das propriedades sensoriais, na firmeza e na formação do complexo amilose-lipídico termoestável, responsável por retardar a retrogradação.

Uma vez que a retrogradação da amilopectina está associada à quantidade de água no pão durante seu armazenamento (ZELEZNAK \& HOSENEY, 1986), a presença da fibra de laranja afetaria este fenômeno, já que possui capacidade de retenção de água superior a do amido, interferindo na distribuição da água no sistema (PURHAGEN et al., 2012). ANGIOLONI \& COLLAR (2009) avaliaram a vida útil de pães elaborados com substituição parcial (0 a 12\%) da farinha de trigo por fibras dietéticas de diferentes fontes (semente de alfarroba, fruto-oligossacarídeos, gluco-oligossacarídeos e carboximetilcelulose) através de testes reológicos, viscosimétricos, análise sensorial e análise de imagem digital, e obtiveram bons resultados de textura e uma forte relação da aceitação global com a textura dos pães. Já em estudo realizado por PURHAGEN et al. (2012), a substituição de 3\% da farinha de trigo por farelos de aveia, trigo e centeio causou efeito negativo na retrogradação do amido, exceto para o farelo de aveia, que não causou o aumento na retrogradação. Os pães adicionados de fibra obtiveram maior perda de água e maiores taxas de retrogradação, causando endurecimento e efeito negativo na sua vida útil. No presente estudo, conclui-se que a adição da $\alpha$-amilase contrapôs os possíveis efeitos negativos causados pela ausência de gordura ou presença da fibra de laranja nos pães, já que as formulações não apresentaram diferença estatisticamente significativa em relação ao IR. Assim, é possível obter pães sem gordura adicionados de até $5 \%$ de fibra de laranja sem redução de vida útil, quando esta adição é combinada ao uso de enzimas na faixa de 10 a 50ppm.

Os valores encontrados para a atividade de água (Tabela 2) são superiores a 0,950, estando de acordo com os obtidos por GRAGNANI (2010), que encontrou valores superiores a 0,900 para os pães de forma com triticale e enzima transglutaminase microbiana. É esperado que ocorra redução na atividade de água no miolo dos pães ao longo de seu período de armazenamento, onde ocorre a migração da água do miolo para o meio externo. CURTI (2010) avaliou pães com farelo de trigo ao longo de sete dias, quando foi observado um aumento na atividade

Tabela 2 - Análise colorimétrica, volume específico e análise sensorial dos pães.

\begin{tabular}{|c|c|c|c|c|c|c|c|c|c|}
\hline \multirow{2}{*}{ Ensaios } & \multicolumn{3}{|c|}{-----------Análise colorimétrica------------ } & \multirow{2}{*}{$\begin{array}{l}\text { Volume } \\
\text { específico } \\
\left(\mathrm{cm}^{3} \mathrm{~g}^{-1}\right)\end{array}$} & \multicolumn{5}{|c|}{ 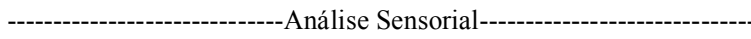 } \\
\hline & $\mathrm{L}^{*}$ & $a^{*}$ & $b^{*}$ & & Cor do miolo & Aroma & Sabor & Textura & $\begin{array}{l}\text { Aceitação } \\
\text { global }\end{array}$ \\
\hline Controle & $73,01 \pm 1,10^{\mathrm{ab}}$ & $-1,42 \pm 0,11^{\text {cd }}$ & $13,85 \pm 0,01^{\mathrm{d}}$ & $3,0 \pm 0,2^{\mathrm{b}}$ & $7,6 \pm 1,0^{\mathrm{a}}$ & $7,2 \pm 1,3^{\mathrm{a}}$ & $7,4 \pm 1,0^{\mathrm{a}}$ & $7,1 \pm 1,5^{\text {a }}$ & $7,4 \pm 1,0^{\mathrm{a}}$ \\
\hline $\mathrm{F} 1$ & $76,93 \pm 0,88^{\mathrm{ab}}$ & $-2,44 \pm 0,14^{\mathrm{a}}$ & $13,17 \pm 0,39^{\mathrm{d}}$ & $3,2 \pm 0,0^{\mathrm{b}}$ & $7,4 \pm 1,1^{\mathrm{a}}$ & $7,0 \pm 1,2^{\mathrm{ab}}$ & $7,3 \pm 1,0^{\mathrm{a}}$ & $6,8 \pm 1,6^{\mathrm{ac}}$ & $7,1 \pm 1,1^{\mathrm{a}}$ \\
\hline $\mathrm{F} 2$ & $70,59 \pm 2,24^{\mathrm{ab}}$ & $-0,82 \pm 0,14^{\mathrm{e}}$ & $21,92 \pm 0,27^{\mathrm{a}}$ & $3,0 \pm 0,1^{\mathrm{b}}$ & $5,8 \pm 1,7^{\mathrm{b}}$ & $6,4 \pm 1,6^{\mathrm{ab}}$ & $4,5 \pm 1,9^{\mathrm{b}}$ & $6,2 \pm 1,6^{\mathrm{bc}}$ & $5,1 \pm 1,7^{\mathrm{c}}$ \\
\hline F3 & $75,26 \pm 0,38^{\mathrm{ac}}$ & $-1,91 \pm 0,0^{\mathrm{b}}$ & $13,7 \pm 0,04^{\mathrm{d}}$ & $3,6 \pm 0,0^{\mathrm{a}}$ & $7,9 \pm 0,9^{\mathrm{a}}$ & $6,8 \pm 1,2^{\mathrm{ab}}$ & $7,0 \pm 1,2^{\mathrm{a}}$ & $6,6 \pm 1,6^{\mathrm{ab}}$ & $6,7 \pm 1,1^{\text {a }}$ \\
\hline F4 & $64,56 \pm 0,41^{\mathrm{b}}$ & $-0,95 \pm 0,16^{\mathrm{e}}$ & $20,27 \pm 0,58^{\mathrm{b}}$ & $3,0 \pm 0,1^{\mathrm{b}}$ & $5,8 \pm 1,6^{b}$ & $6,3 \pm 1,5^{\mathrm{b}}$ & $4,5 \pm 1,8^{b}$ & $5,8 \pm 1,9^{b}$ & $5,1 \pm 1,8^{\mathrm{c}}$ \\
\hline F5 & $67,34 \pm 1,21^{\mathrm{bc}}$ & $-1,71 \pm 0,11^{\mathrm{bd}}$ & $17,73 \pm 0,29^{\mathrm{c}}$ & $3,7 \pm 0,2^{\mathrm{a}}$ & $6,2 \pm 1,5^{b}$ & $6,3 \pm 1,5^{\mathrm{b}}$ & $6,1 \pm 1,6^{\mathrm{c}}$ & $6,2 \pm 1,6^{\mathrm{ab}}$ & $6,1 \pm 1,4^{b}$ \\
\hline
\end{tabular}

*Letras iguais na mesma coluna significam que não houve diferença estatística significativa nos tratamentos entre as médias em nível de 5\% 
Tabela 3 - $\Delta H$ de gelatinização e retrogradação, Índice de Retrogradação e Atividade de Água dos ensaios realizados.

\begin{tabular}{|c|c|c|c|c|c|c|c|}
\hline \multirow{2}{*}{$\begin{array}{l}\text { Ensaios } \\
\text { Controle }\end{array}$} & \multirow{2}{*}{$\frac{\Delta \mathrm{H} \text { gel }\left(\mathrm{J} \mathrm{g}^{-1}\right)}{2,883 \pm 0,380^{\mathrm{a}}}$} & \multirow{2}{*}{$\frac{\Delta \mathrm{H} \operatorname{ret}\left({\left.\mathrm{J} \cdot \mathrm{g}^{-1}\right)}^{\mathrm{a}}\right.}{8,77 \pm 0,96^{\mathrm{a}}}$} & \multirow{2}{*}{$\begin{array}{c}\text { Índice de retrogradação } \\
3,09 \pm 0,61^{\text {a }}\end{array}$} & \multicolumn{2}{|c|}{ Aw (dia 1) } & \multicolumn{2}{|c|}{ Aw (dia 7) } \\
\hline & & & & 0,972 & $\pm 0,002^{\mathrm{Aa}}$ & 0,966 & $\pm 0,001^{\mathrm{Ba}}$ \\
\hline $\mathrm{F} 1$ & $2,498 \pm 0,202^{\mathrm{ab}}$ & $8,92 \pm 0,19^{a}$ & $3,72 \pm 0,18^{\mathrm{a}}$ & 0,965 & $\pm 0,002^{\mathrm{Aa}}$ & 0,966 & $\pm 0,003^{\mathrm{Aa}}$ \\
\hline $\mathrm{F} 2$ & $2,356 \pm 0,317^{\mathrm{ab}}$ & $7,31 \pm 0,48^{a}$ & $3,13 \pm 0,28^{a}$ & 0,969 & $\pm 0,003^{\text {Aab }}$ & 0,958 & $\pm 0,001^{\mathrm{Bb}}$ \\
\hline F3 & $2,299 \pm 0,107^{\mathrm{ab}}$ & $9,07 \pm 0,78^{a}$ & $3,94 \pm 0,16^{\mathrm{a}}$ & 0,966 & $\pm 0,002^{\mathrm{Aab}}$ & 0,957 & $\pm 0,003^{\mathrm{Bc}}$ \\
\hline $\mathrm{F} 4$ & $2,118 \pm 0,167^{b}$ & $7,12 \pm 0,45^{\mathrm{a}}$ & $3,39 \pm 0,48^{\mathrm{a}}$ & 0,972 & $\pm 0,007^{\text {Аa }}$ & 0,963 & $\pm 0,001^{\mathrm{Ab}}$ \\
\hline F5 & $2,766 \pm 0,146^{a b}$ & $8,23 \pm 0,72^{a}$ & $2,98 \pm 0,27^{\mathrm{a}}$ & 0,957 & $\pm 0,008^{\mathrm{Ab}}$ & 0,963 & $\pm 0,003^{\mathrm{Ab}}$ \\
\hline
\end{tabular}

*Letras minúsculas iguais significam que não houve diferença estatística significativa nos tratamentos entre as médias em nível de 5\% de significância. Letras maiúsculas iguais indicam que não houve diferença estatística significativa nas avaliações entre as médias em nível de $5 \%$ de significância.

de água na crosta dos pães e redução na atividade de água do miolo. Esta redução foi observada para a formulação Controle, F2 e F3, após sete dias de armazenamento à temperatura ambiente. Já nas formulações F1, F4 e F5, a atividade de água no miolo manteve-se estável ao longo deste período, indicando que a adição de fibras, acompanhada da adição de um teor igual ou maior a $30 \mathrm{ppm}$ de $\alpha$-amilase, auxilia na manutenção da atividade de água no miolo.

Os pães formulados $(370 \mathrm{~g})$ apresentaram volume específico entre 3,0 e $3,7 \mathrm{~cm}^{3} \mathrm{~g}^{-1}$ (Tabela 3 ). Os maiores valores para volume específico ocorreram para F5, com 2,5\% de fibra de laranja e 30ppm de enzimas, e para F3, sem fibra de laranja e com 50ppm de enzima, ambos sem gordura. Diversos estudos relatam o efeito positivo do uso de enzimas no aumento no volume do pão. A adição de $50 \mathrm{ppm}$ de $\alpha$-amilase fúngica promoveu aumento de volume em estudo realizado por INDRANI et al. (2003), enquanto os pães obtidos através da adição $14 \mathrm{ppm}$ e $30 \mathrm{ppm}$ de $\alpha$-amilase fúngica e bacteriana, respectivamente, também apresentaram aumento de volume, este relacionado à maior elasticidade, menor firmeza, e uma rede de glúten mais aberta nos pães tratados com a enzima (CABALLERO et al., 2007).

As formulações com 5\% de fibra de laranja apresentaram volume inferior às demais, assim como a formulação Controle, que continha gordura, porém não continha enzimas. Apesar de inúmeras pesquisas comprovarem que a adição de alfa-amilase provoca um aumento no volume específico de pães (BONET et al., 2006), no presente estudo, para as formulações onde houve adição de 10ppm e 50ppm de enzima (F2 e F4), este fenômeno não foi observado. Este resultado pode ser explicado pela presença das fibras, já que sua adição em produtos de panificação é comumente relacionada a falhas no processo, como amargor e redução de volume (BERRY, 2004). WANG et al. (2002) estudaram a adição de $3 \%$ de fibras em pães (fibra de alfarroba, fibra de ervilha e inulina), resultando em redução do volume destes, quando comparado ao controle (sem fibras). De acordo com WANG et al. (2002), a redução de volume pode ser explicada através da deformação na massa causada pela presença da fibra, o que reduziria a retenção de $\mathrm{CO}_{2}$. Além disso, certa quantidade de água na massa liga-se fortemente às fibras, podendo interferir na quantidade de água disponível para a formação da rede de glúten (SIVAM, 2010).

A adição de enzima ao nível de 30ppm diminuiu a redução de volume possivelmente ocasionada pela presença de $2,5 \%$ de fibra na formulação F5, demonstrando a eficácia das $\alpha$-amilases no aumento do volume dos pães. Em estudo realizado por KATINA et al. (2005), pães com farelo de trigo adicionados de um combinado de enzimas ( $\alpha$-amilase, xilanase e lipase) também obtiveram bons resultados de volume, alcançando igual volume ao pão sem farelo de trigo (pão branco), enquanto o pão com farelo de trigo não adicionado de enzimas apresentou volume específico inferior.

Quanto à análise sensorial, o painel de provadores foi composto por pessoas de idade entre 18 a 60 anos, sendo 21 do sexo masculino e 29 do sexo feminino. Os resultados obtidos no teste de aceitação da análise sensorial estão relacionados na tabela 3. A textura da formulação F5 (2,5\% de fibra, $30 \mathrm{ppm}$ de enzima) teve igual aceitação à amostra controle, demonstrando que a substituição da gordura pela fibra e enzima nesta faixa de uso foi eficaz. $\mathrm{O}$ sabor das amostras com nível máximo de fibra obteve nota 4,5 , referente a "desgostei levemente" a "não gostei nem desgostei" na escala hedônica. Já a adição de $2,5 \%$ de fibra de laranja obteve nota 6,1 para o atributo sabor, referente a "gostei levemente".

Analisando os dados, pode-se observar que o volume específico de F1, que obteve maior aceitação, foi equivalente ao volume de F2 e F4, de 
menor aceitação. Por isso, acredita-se que o volume específico não foi fator determinante para a aceitação global. Já em relação aos demais atributos sensoriais, tais como aroma, textura, sabor e cor do miolo, obteve-se as menores notas, influenciando na menor aceitação global.

A aceitação global da amostra controle obteve nota 7,4, referente a "gostei moderadamente" a "gostei muito", na escala hedônica (82\% de aceitação), enquanto as amostras com fibra de laranja (F2, F4 e F5) variaram de "gostei levemente" a "gostei moderadamente" (de 70 a 78\% de aceitação). Considerando que, para um produto ser aceito no mercado seu índice de aceitação sensorial deve ser superior a $70 \%$, essas formulações são alternativas viáveis para a indústria de panificação.

\section{CONCLUSÃO}

A fibra de laranja mostrou ser um ingrediente que pode ser utilizado na indústria de panificação, como substituto de gordura, sem causar alterações qualitativas frente aos aspectos tecnológicos dos pães. Sua utilização conjunta com a enzima $\alpha$-amilase, na faixa de $10 \mathrm{ppm}$ a $50 \mathrm{ppm}$, conservou características como volume e vida útil dos pães. A utilização de $2,5 \%$ de fibra de laranja e 30 ppm de $\alpha$-amilase permitiu a obtenção de pães de forma com fibras, livres de gordura, com volume, sabor e textura aceitáveis, e aceitação global em torno de $80 \%$, o que o torna mercadologicamente viável.

\section{COMITÊ DE ÉTICA}

Para participar da pesquisa, todos os provadores assinaram o Termo de Consentimento Livre e Esclarecido, aprovado pelo Comitê de Ética em Pesquisa da UFRGS (Protocolo no 21912).

\section{AGRADECIMENTOS}

Ao Instituto de Ciência e Tecnologia de Alimentos (ICTA/UFRGS), pelo suporte recebido.

\section{REFERÊNCIAS}

ANGIOLONI, A.; COLLAR, C. Gel, dough and fibre enriched fresh breads: Relationships between quality features and staling kinetics. Journal of Food Engineering, v.91, p.526-532, 2009. Disponível em: <http://www.sciencedirect.com/science/article/pii/ S0260877408004937>. Acesso em: 20 fev 2013. doi: 10.1016/j. jfoodeng.2008.09.033.

BABOOTA, R.K. et al. Functional food ingredients for the management of obesity and associated co-morbidities - A review. Journal of Functional Foods, v.5, p. 997-1012, 2013.
Disponível em: <http://www.sciencedirect.com/science/article/pii/ S1756464613001217>. Acesso em: 20 fev. 2013. doi: 10.1016/j. jff.2013.04.014.

BENASSI, V.T. et al. Produtos de panificação com conteúdo calórico reduzido. Boletim CEPPA, v.19, n.2, p.225-242, 2001. Disponível em: <http://ojs.c3sl.ufpr.br/ojs2/index.php/alimentos/ article/view/1235>. Acesso em 22 jan. 2013. doi: 10.5380\%2Fcep. v19i2.1235.

BONET, A. et al. Glucose oxidase effect on dough rheology and bread quality: a study from macroscopic to molecular level. Food Chemistry, v.99, n.2, p.408-415, 2006. Disponível em: <http:// www.sciencedirect.com/science/article/pii/S0308814605006254> Acesso em 30 out. 2012. doi: 10.1016/j.foodchem.2005.07.043.

BORTOLUZZI, R.C. Aplicação de fibra obtida da polpa da laranja na elaboração de mortadela de frango. 2009. 112f. Tese (Doutorado em Ciência dos Alimentos - Bromatologia) Universidade de São Paulo, São Paulo, SP.

CABALLERO, P.A. et al. Improvement of dough rheology, bread quality and bread shelf-life by enzymes combination. Journal of Food Engineering, v.81, n.1, p.42-53, 2007. Disponível em: $<$ http:// www.sciencedirect.com/science/article/pii/S0260877406006376>. Acesso em: 20 dez. 2012. doi: 10.1016/j.jfoodeng.2006.10.007.

CALVEL, R.; WIRTZ, R.L. The taste of bread. Maryland: Springer, 2001. 207 p.

CURTI, E. The state of water in bread: effect of processing, formulation and storage. 2010. 130f. Tese (Doutorado em Food Science and Technology) - Universita' degli studi di Parma, Italy.

FERNANDEZ-LÓPEZ, J. et al. Storage stability of a high dietary fibre powder from orange by-products. International Journal of Food Science and Technology, v.44, p.748-756, 2009. Disponível em: <http://onlinelibrary.wiley.com/doi/10.1111/j.13652621.2008.01892.x/abstract>. Acesso em 18 dez. 2012. doi: 10.1111/j.1365-2621.2008.01892.x.

FORKER, A. et al. A combination of fat replacers enables the production of fat-reduced shortdough biscuits with high-sensory quality. Food And Bioprocess Technology, v.5, n.6, p.2497-2505, 2012. Disponível em: <http://onlinelibrary.wiley.com/doi/10.1111/ ijfs.12617/pdf>. Acesso em 20 dez. 2012. doi: 10.1111/ijfs.12617.

GRAGNANI, M. A. L. Produção e avaliação de pão de forma com triticale e enzima transglutaminase microbiana. 2010. 167f. Dissertação (Mestrado em Tecnologia de Alimentos) Faculdade de Engenharia de Alimentos, Universidade Estadual de Campinas, Campinas, SP.

INDRANI, D. et al. Scanning electron microscopy, rheological characteristics, and bread-baking performance of wheat-flour dough as affected by enzymes. Journal of Food Science, v.68, n.9, p.2804-2809, 2003. Disponível em: <http://onlinelibrary.wiley. com/doi/10.1111/j.1365-2621.2003.tb05809.x/abstract>. Acesso em 21 dez. 2012. doi: 10.1111/j.1365-2621.2003.tb05809.x.

KATINA, K. et al. Effects of sourdough and enzymes on staling of high-fibre wheat bread. Swiss Society of Food Science and Technology, v.39, p.479-491, 2005. Disponível em: <http://www. sciencedirect.com/science/article/pii/S0023643805000654>. Acesso em 18 dez. 2012. doi: 10.1016/j.lwt.2005.03.013. 
LEÓN, A. et al. A new approach to study starch changes occurring in the dough-baking process and during bread storage. Zeitschrift fuer Lebensmittel-Untersuchung und Forschung, n.204. p.316320, 1997.

LEÓN, A. et al. Utilization of enzyme mixtures to retard bread crumb firming. Journal of Agricultural and Food Chemistry, v.50, p.1416-1419, 2002. Disponível em: <http:// download.springer.com/static/pdf/433/art\%253A10.1007\%252 Fs002170050083.pdf?auth66=1409490050_1f28cf395cbb003d ce304316943dd962\&ext=.pdf>. Acesso em 25 nov. 2012. doi: $10.1007 / \mathrm{s} 002170050083$.

PURHAGEN, J.K. et al. Fibre-rich additives: the effect on staling and their function in free-standing and pan-baked bread. Journal of Science and Food Agriculture, v.92, p.12011213, 2012. Disponível em: < http://www.ncbi.nlm.nih.gov/ pubmed/22052714>. Acesso em: 20 out. 2012. doi: 10.1002/ jsfa.4684.

ROMERO-LOPEZ, M.R. et al. Fiber concentrate orange (Citrus sinensis L.) bagase: characterization and application as bakery product ingredient. International Journal of Molecular Science v.12, p.2174-2186, 2011. Disponível em <http://www.ncbi.nlm. nih.gov/pubmed/21731434>. Acesso em: 28 out. 2012. doi: 10.3390/ijms 12042174 .

SANTANA, M.F.S.; GASPARETTO, C.A. Microestrutura da fibra alimentar do albedo de laranja: um estudo por técnicas físicas e análise de imagens. Ciência e Tecnologia de Alimentos, v.29, n.1, p.124-134, 2009. Disponível em <http://www.scielo.br/ scielo.php?script $=$ sci_arttext\&pid $=\mathrm{S} 0101-20612009000100020>$. Acesso em 26 out. 2012. doi: 10.1590/S0101-20612009000100020.

SILVA, M.R. et al. Utilização da farinha de jatobá (Hymenaea stigonocarpa Mart.) na elaboração de biscoitos tipo cookie e avaliação de aceitação por testes sensoriais afetivos univariados e multivariados. Ciência e Tecnologia de Alimentos, v.18, n.1, p.25-34, 1998. Disponível em: <http://www.scielo.br/scielo. php script $=$ sci arttext\&pid $=S 0101-20611998000100007>$. Acesso em: 18 out. 2012. doi: 10.1590/S0101-20611998000100007.

SINGH, J. et al. Factors influencing the physico-chemical, morphological, thermal and rheological properties of some chemically modified starches for food applications - A review. Food Hydrocolloids, v.21, p.1-22, 2007. Disponível em <http://www. sciencedirect.com/science/article/pii/S0268005X0600049X $>$. Acesso em 30 out. 2012. doi: 10.1016/j.foodhyd.2006.02.006.

SIVAM, A.S. et al. Properties of bread dough with added fiber polysaccharides and phenolic antioxidants: a review. Journal of Food Science, v.75, n.8, p.163-174, 2010. Disponível em: <http:// www.ncbi.nlm.nih.gov/pmc/articles/PMC3032915/> Acesso em: 12 out. 2012. doi: 10.1111/j.1750-3841.2010.01815.x.

STAUFFER, C.E. Principles of dough formation. In: CAUVAIN, S.P.; YOUNG, L.S. Technology of breadmaking. US: Springer, 2007. Cap.11, p.299-332.

WANG, J. et al. Effect of the addition of different fibres on wheat dough performance and bread quality. Food Chemistry, v.79, p.221-226, 2002. Disponível em $<$ http://www.sciencedirect.com/ science/article/pii/S0308814602001358>. Acesso em: 2 nov. 2012. doi: 10.1016/S0308-8146(02)00135-8.

ZELEZNAK, K.J.; HOSENEY, R.C. The role of water in the retrogradation of wheat starch gels and bread crumb. American Association of Cereal Chemists, v.63, n.5, p.407-411, 1986. Disponível em: <http://www.aaccnet.org/ publications/cc/backissues/1986/Documents/chem63 407. pdf $>$. Acesso em 3 nov. 2012. 